\title{
An Effective Method to Facilitate Personalized and Precise Medicine for Schizophrenia Treatment Based on Pharmacogenomics
}

\section{Yixiang Shi}

Shanghai Conlight Medical Institute https://orcid.org/0000-0002-2138-1004

\section{Xiong Zhang}

Hulunbuir Mental Health Center

\section{Xiaoping Gu}

Shanghai Conlight Medical Institute

\section{Chengchen Huang}

Shanghai Conlight Medical Institute

\section{Yue Zhang}

Shanghai Conlight Medical Institute

Dong-dong Qi ( $D$ 1420352185@qq.com )

Hulunbuir Mental Health Center, Yakeshi

\section{Research article}

Keywords: schizophrenia, second generation antipsychotics, MassArray, genetic test , clinical study

Posted Date: September 15th, 2020

DOl: https://doi.org/10.21203/rs.3.rs-64915/v1

License: (9) (i) This work is licensed under a Creative Commons Attribution 4.0 International License. Read Full License 


\section{Abstract}

Background: Schizophrenia is a serious mental illness affecting $0.3 \%-0.7 \%$ of people in the whole world. It is a classic quantitative genetic disease and is affected by a variety of common and rare genetic variants.

Methods: To facilitate personalized and precise medicine for schizophrenia treatment, we designed a program by genotyping a panel of related genes, including cytochrome P450 genes CYP1A2, CYP2D6, CYP3A4, dopamine 2 receptor gene (DRD2), 5-Hydroxytryptamine Receptor $1 \mathrm{~A}$ and $2 \mathrm{C}$ genes (HTR1A and HTR2C) as well as melanocortin4 receptor (MC4R) gene, for the schizophrenia patients using MassArray time-of-flight mass spectrometry.

Results: The program is tested in an observational clinical study conducted at the Hulunbuir Mental Health Center of China. In the study, a total of 254 patients diagnosed with schizophrenia were recruited and genotyped. The genotyping results were used to generate reports listing where the 16 included antipsychotics should be placed: 'Use as directed', 'Use with caution' or 'Use with caution and with frequent blood concentration monitoring' columns. However, the medication would not change regardless. 72 of the patients completed the 24-week follow-up observation, during which their PANSS scores were assessed at eight time points. For all of them, the PANSS scores dropped significantly, showing the effectiveness of the treatments. The treatments for those cohorts initially in the 'Use with caution' or 'Use with caution and with frequent blood concentration monitoring' categories were more effective than those in the 'Use as directed' category in a shorter term sense, up to three months. However, in the longer term, it was still those who were initially in the 'Use as directed' column fared better, whose PANSS scores dropped more significantly.

Conclusions: This research indicated that our pharmacogenomic-based program could be a suitable and effective tool to facilitate precise medicine in schizophrenia treatment.

\section{Background}

Schizophrenia is a serious chronic persistent mental illness with a global incidence of about $0.3 \%-0.7 \%$ [1]. The disease mostly occurs in late adolescence or early adulthood and shows varying degrees of social or occupational functional impairment. Researches demonstrated that the causes of schizophrenia included genetic factors, psychological factors and environmental factors[2]. There were evidences implying that $70 \%-80 \%$ of the individual differences in risk to schizophrenia are associated with genetics[3]. However, the current treatment of schizophrenia has not yet taken the genetic variation sufficiently into account.

The essence of clinical drug treatment is basically a process of effective drug use. Both human body conditions (age, gender, physiology, pathology, genetics of the patients) and drugs (dose, dosage form, administration time, dosing interval, combination medication) could be the master factors affecting the final therapeutic effect of drugs[4]. More and more studies demonstrate that genetic factors maybe play 
the most important role in affecting the differential response of drugs. Pharmacogenomics studies the role of genome in drug response and analyzes how the genetic makeup of an individual affects his/her response to drugs by correlating genetic variation and gene expression level with pharmacokinetics (drug absorption, distribution, metabolism, and elimination) and pharmacodynamics (effects mediated through a drug's biological targets). The application of pharmacogenomics and big data analysis in psychiatric research will provide the patients with mental disorders an important drug therapy for individualized medication and reduce the incidence of adverse reactions, thus promote the advancement of precision medicine [5-7].

Major depressive disorder (MDD) is another complex psychiatric diseases that bother millions of people around the world. In the past decades, several algorithms have been developed to guide the medication based on patients' genetic test results, for example, Genesight[8-15] and IMPACT (Individualized Medicine: Pharmacogenetics Assessment and Clinical Treatment)[16]. GeneSight tests the genetic polymorphisms of several selected genes, mostly are related to MDD drug metabolism, efficacy or adverse drug reactions (ADRs). In the large scale clinical trial published in 2019[14], 1167 MDD patients were randomly assigned into two groups, the treatment of one group was conducted under the guidance of GeneSight recommendations based on genetic test results, the other followed the traditional nonguided treatment protocol. Each patient were evaluated regularly using 17-item Hamilton Depression Scale (HAMD-17) to assess how serious his/her depression was during the trial period. After 8-week observation, the response rate (defined as HAMD-17 score dropped more than $50 \%$ ) in the guided group was $30 \%$ higher than that of the non-guided group, while the remission rate (defined as HAMD-17 score dropped below 7) was $50 \%$ higher in the guided group over the non-guided group. The results demonstrated that pharmacogenomics had the potential to guide rational drug therapy to facilitate personalized and precise medicine.

To our best knowledge, there is no clinical study published in which GeneSight-like program was used for guiding schizophrenia drug prescription based on genetic test. In this paper, we describe a program we developed and the results of an observational clinical study we carried out in Hulunbuir Mental Health Center, China. Although this is not a randomized perspective study exactly like the ones performed by GeneSight, it does offer valuable information and its usefulness may be further proved by larger-scale, double-blinded, multi-centered trials in the near future.

\section{Methods}

\section{Program design}

This program is designed to assist physicians to better prescribe antipsychotics and ensure maximum efficiency with minimal adverse effects based on patients' genotypes. A total of 16 drugs are included in the package: amisulpride, aripiprazole, clozapine, olanzapine, paliperidone, quetiapine, risperidone, ziprasidone, haloperidol, perphenazine, thioridazine, zuclopenthixol, sulpiride, loxapine, chlorpromazine and perospirone. Some of them are typical antipsychotics (perphenazine, thioridazine, et al). Some are 
second-generation antipsychotics (SGA), also called atypical antipsychotics, including risperidone, quetiapine, olanzapine, ziprasidone, and aripiprazole et al. Genes were selected based on FDA specifications, CPIC (the Clinical Pharmacogenetics Implementation Consortium) official guidelines, clinical study data, authoritative literature, and relevant genome databases. The candidate gene loci are all based on the characteristics and distribution frequency of Asians especially Chinese people. The nucleotide polymorphisms of antipsychotics-related genes including CYP2D6, CYP1A2, CYP3A4, DRD2, HTR1A, HTR2C and MC4R, which affects the metabolism, efficacy and side effects of most antipsychotics, have been detected (supplementary table).

After genotyping, each genotype for each genetic loci is assigned a weight according to an in-house algorithm, based on how much this loci may impact the metabolism, efficacy or ADR for a particular medicine. Then a fitness score is calculated for each drug. If the score for a drug is above 80 , it will be placed in the 'Use as directed' column in our interpretive report; if the score is between 60 to 80 , it is put in the 'Use with caution' column; if the score is below 60 , it will be in the 'Use with caution and with frequent blood concentration monitoring' column. Therefore, the physician and the tested patient may get a report like this: (Figure 1). If the drug currently used was in the 'Use with caution' or 'Use with caution and with frequent blood concentration monitoring' columns, the physician in charge may have the option to choose another antipsychotics.

\section{Genotyping}

Epithelial cells was gathered by buccal swab at baseline, and the samples were then transported from the hospital to the laboratory in the Shanghai Conlight Medical Institute on the same day. Genomic DNA was extracted according to the standard phenol-chloroform procedure and analyzed using TaqMan probePCR and MassArray iPlex platform (Agena Bioscience Inc., San Diego, CA, USA). Polymerase chain reaction (PCR) was applied to amplify the relevant genomic regions. The primers of PCR were designed using Primer Premier5 (Premier Biosoft International, Palo Alto, CA, USA) and synthesized by Sangon Biotech. (Shanghai, China). Genotyping of single nucleotide polymorphisms was conducted by ABI 7500 real-time fluorescence quantitative PCR combined with TaqMan probe and arms-PCR. MassARRAY DNA based on Matrix Assisted Laser Desorption/Ionization-Time of Flight Mass Spectrometry was employed to accurately identify mutation types. The CYP2D6 alleles identified were: $* 1, * 2, * 2 \mathrm{~A}, * 3, * 4, * 5, * 6$, $* 7, * 8, * 9, * 10, * 11, * 12, * 14 \mathrm{~A}, * 14 \mathrm{~B}, * 15, * 17, * 36, * 41$ and CNV. The identified CYP1A2 alleles were: $* 1, * 1 \mathrm{C}, * 1 \mathrm{E}, * 1 \mathrm{~F}, * 1 \mathrm{~K}, * 3, * 4, * 6, * 7, * 8, * 11, * 15$, and $* 16$. The identified CYP3A4 alleles were: $* 1, * 20$. The metabolizer status for CYP2D6, CYP1A2 and CYP3A4 are determined according to the same methods reported in previous researches: subjects with more than two active alleles were classified as ultra-rapid metabolizers, while those with at least one active allele were classified as extensive metabolizers. Subjects carrying two alleles of decreased activity or compound heterozygotes for one decreased activity allele in combination with a non-functional allele were termed as intermediate metabolizers. A combination of two non-functional alleles in a homozygous variant or compound heterozygous manner was classified as a poor metabolizers phenotype[17-20]. The identified DRD2 
alleles were single nucleotide polymorphisms rs1079597, rs1799732 and rs1799978. Rs1414334 and rs6318 of HTR2C, rs10042486 of HTR1A, as well as the SNP rs489693 on the gene MC4R were also genotyped. Within $72 \mathrm{~h}$ of sample collection, the pharmacogenomic-based report was offered to the treating psychiatrist.

\section{Clinical study}

To test our program, we conducted a clinical study in Hulunbuir Mental Health Center. Patients met these criteria were enrolled: (1) Chinese citizen aged 18-70 years; (2) patients whom are diagnosed of schizophrenia based on the Structured Clinical Interview of DSM-IV; (3) $\geq 60$ on the Positive and Negative Syndrome Scale (PANSS) (and $\geq 4$ on at least three positive items); (4) physically healthy with all laboratory parameters within normal limits. Patients were excluded if they met any of the following exclusion criteria: (1) diagnosis of other psychiatric disorders (such as schizoaffective disorder and delusional disorder) or cognitive disorders (such as dementia and amnesia); (2) severe, unstable physical diseases (such as diabetes, thyroid diseases, hypertension, and cardiac diseases); (3) history of druginduced neuroleptic malignant syndrome; (4) requiring long-acting injectable medication to maintain treatment adherence; (5) treated with electroconvulsive therapy during the last month; (6) previous attempted suicide, previous symptoms of severe excitement and agitation; (7) pregnant or breastfeeding; (8) contraindication to any of the drugs included in this study. The pharmacogenomic testing was offered free of charge to the study participants and any of them can opt out at any given time.

254 patients are initially enrolled. Written informed consents to participate were obtained from both the patients and their legal guardians. We genotyped a panel of related genomic polymorphisms using MassArray time-of-flight mass spectrometry and test reports are generated as described in the 'Program Design' section. While in general cases, the treating physicians may decide to change medication based on the test report, in this observational study the medication would not change unless there were serious adverse reactions. If medication was changed, the patient would be removed from further observation. The patients were observed at 8 time points: baseline (week 0, before treatment and genetic test), week2 (two weeks after genetic test, same below), week4, week8, week12, week16, week20 and week24. At each time point, their PANSS scores were assessed. Among the 254 cohorts initially enrolled, 71 were removed due to lack of essential information (whether they have other physical diseases, et al). 31 patients dropped out (or were removed) during various stages and 152 completed the 24-week observation. Two more are later removed because their ages are below 18. For the remaining 150 enrolled patients, we focused on those who were prescribed with single second-generation antipsychotics including olanzapine, quetiapine, aripiprazole and clozapine, and 58 patients whom were either prescribed with other drugs or combinatorial medication were removed. Another 20 patients are removed because they are ethnic minority (see 'Discussions' section) and 72 ethnic Han Chinese remained in the final study. Among them, 48 (66.7\%) were 'Use as directed' and the others (24, 33.3\%) were either 'Use with caution' or 'Use with caution and with frequent blood concentration monitoring'. (Figure 2) 


\section{Measurements and Statistics}

Demographic characteristics (such as age and gender) and disease-related characteristics (such as severity of illness assessed by PANSS, DOI (duration of illness, months), and medication history) were recorded.

Descriptive statistics were used to summarize the demographic and clinical characteristics. Nominal variables were shown as counts (percentage), continuous variables were shown as mean (standard error). Independence between genotypes and treatment groups was analyzed with Fisher's exact test or Chi-square test. Total PANSS scores between groups were compared with independent t-test for each visit. We also divided participants into two groups based on PANSS improvement with a cutoff value of 25, 50 or 75. Fisher's exact test or Chiq-square test was used to determine the association between PANSS improvement groups and treatment groups. All analyses were performed using R package (version 3.5.1). $\mathrm{P}<0.05$ was considered statistically significant.

\section{Results}

\section{Demographic and clinical variables}

For the 72 cohorts who completed the final study, 48 of them got genetic test reports consistent with their treatment, while another 24 were inconsistent. The 'consistent' group has 43 males (89.6\%) and 5 females (10.4\%), while the 'inconsistent' group has 18 males $(75.0 \%)$ and 6 females $(25.0 \%)$. The average ages for the 72 cohorts are 43.7, 41.4 for the 'consistent' group and 48.3 for the 'inconsistent' group. Other baseline information are listed in the Table 1. 
Table 1

Demographic and clinical characteristics

\begin{tabular}{|lcllll|}
\hline & Total & Clozapine & Olanzapine & Quetiapine & Aripiprazole \\
\hline N & 72 & 47 & 7 & 13 & 5 \\
\hline Age (Mean \pm SD) & $43.7 \pm 11.6$ & $42.7 \pm 10.2$ & $49.4 \pm 16.3$ & $47.7 \pm 11.8$ & $34.4 \pm 12.5$ \\
\hline Gender & & & & & \\
\hline Male (\%) & $61(84.7 \%)$ & $42(68.9 \%)$ & $6(9.8 \%)$ & $11(18.0 \%)$ & $2(3.3 \%)$ \\
\hline Female (\%) & $11(15.3 \%)$ & $5(45.5 \%)$ & $1(9.1 \%)$ & $2(18.2 \%)$ & $3(27.3 \%)$ \\
\hline PANSS baseline & $83.2 \pm 11.8$ & $83.2 \pm 11.9$ & $79.0 \pm 11.4$ & $85.8 \pm 13.3$ & $82.2 \pm 8.2$ \\
\hline Group & & & & & \\
\hline Consistent (\%) & $48(66.7 \%)$ & $37(77.1 \%)$ & $3(6.2 \%)$ & $6(12.5 \%)$ & $2(4.2 \%)$ \\
\hline Inconsistent (\%) & $24(33.3 \%)$ & $10(41.7 \%)$ & $4(16.7 \%)$ & $7(29.2 \%)$ & $3(12.5 \%)$ \\
\hline Abbreviations: N, numbers of samples; PANSS, Positive and Negative Syndrome Scale; \\
\hline Continuous variables are expressed as mean \pm sd. categorical variables are expressed as N (\%). \\
\hline
\end{tabular}

\section{The Drug Metabolizing Enzyme Genotypes}

The genotypes of CYP2D6, CYP1A2 and CYP3A4 were obtained. We also identified the metabolic capacity (ultra-rapid, extensive, intermediate or poor metabolizers) for each cohort based on the activities of enzymes encoded by the above 3 genes (Table 2).

For the cohorts in the 'consistent' group, their CYP2D6 metabolic capacity phenotypes were $62.5 \%$ extensive metabolizers, $35.4 \%$ intermediate metabolizers, $2.1 \%$ poor metabolizers. Their CYP1A2 metabolic capacity phenotypes were $62.5 \%$ extensive metabolizers and $37.5 \%$ ultra-rapid metabolizers. Their CYP3A4 metabolic capacity phenotypes were 100\% extensive metabolizers.

For the cohorts in the 'inconsistent' group, their CYP2D6 metabolic capacity phenotypes were $50.0 \%$ extensive metabolizers, $45.8 \%$ intermediate metabolizers, $4.2 \%$ poor metabolizers. Their CYP1A2 metabolic capacity phenotypes were $50.0 \%$ ultra-rapid metabolizers, $45.8 \%$ extensive metabolizers, $4.2 \%$ intermediate metabolizers. Their CYP3A4 metabolic capacity phenotypes were $91.7 \%$ extensive metabolizers and $8.3 \%$ intermediate metabolizers.

The percentage distributions for the genotypes of these metabolic enzymes are generally within the expected normal ranges for Chinese population. There are no statistically significant difference between these frequencies in the two groups. 
Table 2

Metabolic Capacity Phenotype frequency by Treatment Group

\begin{tabular}{|c|c|c|c|}
\hline Gene & Consistent $(\mathrm{N}=48)$ & Inconsistent $(\mathrm{N}=24)$ & P-value \\
\hline \multicolumn{4}{|c|}{ CYP1A2 } \\
\hline UM & 18 & 12 & \multirow[t]{4}{*}{0.152} \\
\hline EM & 30 & 11 & \\
\hline IM & 0 & 1 & \\
\hline PM & 0 & 0 & \\
\hline \multicolumn{4}{|c|}{ CYP2D6 } \\
\hline UM & 0 & 0 & \multirow[t]{4}{*}{0.44} \\
\hline EM & 30 & 12 & \\
\hline IM & 17 & 11 & \\
\hline PM & 1 & 1 & \\
\hline \multicolumn{4}{|c|}{ CYPЗА4 } \\
\hline UM & 0 & 0 & \multirow[t]{4}{*}{0.108} \\
\hline EM & 48 & 22 & \\
\hline IM & 0 & 2 & \\
\hline PM & 0 & 0 & \\
\hline \multicolumn{4}{|c|}{$\begin{array}{l}\text { Abbreviations: CYP1A2, cytochrome P450 } 1 \text { A2 gene; CYP2D6, cytochrome P450 } 2 \mathrm{D} 6 \text { gene; CYP3A4, } \\
\text { cytochrome P450 } 3 \mathrm{~A} 4 \text { gene; UM, Ultra-rapid Metabolizer; EM, Extensive Metabolizer; IM, Intermediat } \\
\text { Metabolizer; PM, Poor Metabolizer. }\end{array}$} \\
\hline \multicolumn{4}{|c|}{ P-values were obtained by Fisher's exact test. } \\
\hline
\end{tabular}

\section{Target Genotypes}

We genotyped the polymorphisms of rs1079597, rs1799978 and rs1799732 on the gene DRD2, rs10042486 on the gene HTR1A, rs1414334 and rs6318 on the gene HTR2C, as well as rs489693 on the gene MC4R.

For the cohorts in the 'consistent' group, their rs1079597 genotype distribution frequency is $33.3 \% \mathrm{C} / \mathrm{C}$, $41.7 \% \mathrm{C} / \mathrm{T}$ and $25 \% \mathrm{~T} / \mathrm{T}$. Their rs 1799978 genotype frequency is $4.2 \% \mathrm{C} / \mathrm{C}, 33.3 \% \mathrm{C} / \mathrm{T}$ and $62.5 \% \mathrm{~T} / \mathrm{T}$. Their rs 1799732 genotype frequency is $4.2 \% \mathrm{G} /-, 95.8 \% \mathrm{G} / \mathrm{G}$. Their rs 10042486 genotype frequency is 
$2.1 \% \mathrm{C} / \mathrm{C}, 27.1 \% \mathrm{C} / \mathrm{T}$ and $70.8 \% \mathrm{~T} / \mathrm{T}$. Their rs 1414334 genotype frequency is $100 \% \mathrm{G} / \mathrm{G}$. Their rs 6318 genotype frequency is also $100 \% \mathrm{G} / \mathrm{G}$. Their rs489693 genotype frequency is $29.2 \% \mathrm{~A} / \mathrm{C}, 70.8 \% \mathrm{C} / \mathrm{C}$.

For the cohorts in the 'inconsistent' group, their rs 1079597 genotype distribution frequency is $33.3 \% \mathrm{C} / \mathrm{C}$, $58.3 \% \mathrm{C} / \mathrm{T}$ and $8.4 \% \mathrm{~T} / \mathrm{T}$. Their rs 1799978 genotype frequency is $4.2 \% \mathrm{C} / \mathrm{C}, 20.8 \% \mathrm{C} / \mathrm{T}$ and $75 \% \mathrm{~T} / \mathrm{T}$. Their rs 1799732 genotype frequency is $4.2 \%-/-, 50 \%$ G/-, 45.8\% G/G. Their rs 10042486 genotype frequency is $8.4 \% \mathrm{C} / \mathrm{C}, 45.8 \% \mathrm{C} / \mathrm{T}$ and $45.8 \% \mathrm{~T} / \mathrm{T}$. Their $\mathrm{rs} 1414334$ genotype frequency is $95.8 \% \mathrm{G} / \mathrm{G}$ and $4.2 \% \mathrm{C} / \mathrm{G}$. Their rs 6318 genotype frequency is also $95.8 \% \mathrm{G} / \mathrm{G}$ and $4.2 \% \mathrm{C} / \mathrm{G}$. Their rs 489693 genotype frequency is $4.2 \% \mathrm{~A} / \mathrm{A}, 20.8 \% \mathrm{~A} / \mathrm{C}, 75 \% \mathrm{C} / \mathrm{C}$. Among these sites, only the distribution frequency of rs1799732 on the gene DRD2 is statistically significantly different between the two groups. 
Table 3

Drug Efficacy and ADR related loci frequency by Treatment Group

\begin{tabular}{|c|c|c|c|}
\hline Gene / SNP & Consistent $(\mathrm{N}=48)$ & Inconsistent( $\mathrm{N}=24)$ & P-value \\
\hline \multicolumn{4}{|c|}{ DRD2 / rs1079597 } \\
\hline $\mathrm{C} / \mathrm{C}$ & 16 & 8 & \multirow[t]{3}{*}{0.211} \\
\hline $\mathrm{C} / \mathrm{T}$ & 20 & 14 & \\
\hline $\mathrm{T} / \mathrm{T}$ & 12 & 2 & \\
\hline \multicolumn{4}{|c|}{ DRD2 / rs1799978 } \\
\hline $\mathrm{C} / \mathrm{C}$ & 2 & 1 & \multirow[t]{3}{*}{0.61} \\
\hline $\mathrm{C} / \mathrm{T}$ & 16 & 5 & \\
\hline $\mathrm{T} / \mathrm{T}$ & 30 & 18 & \\
\hline \multicolumn{4}{|c|}{ DRD2 / rs1799732 } \\
\hline$-/-$ & 0 & 1 & \multirow[t]{3}{*}{$<0.001$} \\
\hline G/- & 2 & 12 & \\
\hline $\mathrm{G} / \mathrm{G}$ & 46 & 11 & \\
\hline \multicolumn{4}{|c|}{ HTR1A / rs10042486 } \\
\hline $\mathrm{C} / \mathrm{C}$ & 1 & 2 & \multirow[t]{3}{*}{0.073} \\
\hline $\mathrm{C} / \mathrm{T}$ & 13 & 11 & \\
\hline $\mathrm{T} / \mathrm{T}$ & 34 & 11 & \\
\hline \multicolumn{4}{|c|}{ HTR2C / rs1414334 } \\
\hline $\mathrm{C} / \mathrm{C}$ & 0 & 0 & \multirow[t]{3}{*}{0.333} \\
\hline $\mathrm{C} / \mathrm{G}$ & 0 & 1 & \\
\hline $\mathrm{G} / \mathrm{G}$ & 48 & 23 & \\
\hline \multicolumn{4}{|c|}{ HTR2C / rs6318 } \\
\hline $\mathrm{C} / \mathrm{C}$ & 0 & 0 & \multirow[t]{3}{*}{0.333} \\
\hline $\mathrm{C} / \mathrm{G}$ & 0 & 1 & \\
\hline $\mathrm{G} / \mathrm{G}$ & 48 & 23 & \\
\hline \multicolumn{4}{|c|}{ MC4R / rs489693 } \\
\hline $\mathrm{A} / \mathrm{A}$ & 0 & 1 & \multirow[t]{2}{*}{0.365} \\
\hline $\mathrm{A} / \mathrm{C}$ & 14 & 5 & \\
\hline
\end{tabular}


Abbreviations: ADR, adverse drug reaction; DRD2, dopamine 2 receptor gene; HTR1A, 5Hydroxytryptamine Receptor 1A gene; HTR2C, 5-Hydroxytryptamine Receptor 2C gene; MC4R, melanocortin4 receptor gene. SNP, single nucleotide polymorphism site.

P-values were obtained by Fisher's exact test.

\section{Treatment Effectiveness}

As indicated in Figure 3, for the cohorts in either the 'consistent' or the 'inconsistent' groups at the baseline, the PANSS scores have no statistically significant difference. For both groups, the PANSS scores dropped significantly after 24-week treatment, more than 30\% (Table4, Table5, and Figure 3, Figure 4).

Suprisingly, the PANSS scores for the cohorts in the 'inconsistent' group dropped faster than for those in the 'consistent' group (Table4, Table5, and Figure 3, Figure 4). This phenomenon is statistically significant at the time point 2 (two weeks after the baseline check), notable but not statistically significant at the time points 3 (four weeks after), 4 (eight weeks after) and 5 (twelve weeks after). The trend starts to reverse after that.

Table 4

PANSS scores at seven examining points (after baseline)

\begin{tabular}{|c|c|c|c|c|c|c|c|c|}
\hline \multirow[t]{2}{*}{ Time Point } & \multicolumn{2}{|c|}{ Consistent } & \multicolumn{2}{|c|}{ Inconsistent } & \multicolumn{2}{|l|}{ F-test } & \multicolumn{2}{|l|}{ t-test } \\
\hline & Mean & std & Mean & std & F-value & P-value & t-value & P-value \\
\hline 2 & 81.85 & 1.88 & 74.96 & 2.43 & 1.191 & 0.663 & 2.178 & 0.033 \\
\hline 3 & 78.31 & 1.78 & 72.46 & 2.68 & 0.885 & 0.704 & 1.855 & 0.068 \\
\hline 4 & 73.71 & 1.69 & 68.04 & 2.38 & 1.002 & 0.972 & 1.94 & 0.056 \\
\hline 5 & 69.25 & 1.63 & 66.21 & 2.01 & 1.307 & 0.494 & 1.123 & 0.265 \\
\hline 6 & 66.19 & 1.63 & 67.08 & 1.56 & 2.181 & 0.046 & -0.397 & 0.693 \\
\hline 7 & 59.31 & 2.07 & 65.33 & 1.79 & 2.689 & 0.012 & -2.2 & 0.031 \\
\hline 8 & 58.83 & 2.21 & 63.83 & 2.06 & 2.319 & 0.032 & -1.654 & 0.103 \\
\hline \multicolumn{9}{|c|}{ Abbreviations: PANSS, Positive and Negative Syndrome Scale. } \\
\hline \multicolumn{9}{|c|}{ Baseline was defined as Time Point 1.} \\
\hline \multicolumn{9}{|c|}{$\begin{array}{l}\text { F-test was used for Homogeneity of variance test; } t \text {-test was used to compare the means between } \\
\text { groups at each time point. }\end{array}$} \\
\hline
\end{tabular}


Table 5

PANSS change rate

\begin{tabular}{|lllllllll|}
\hline Time Point & \multicolumn{2}{l}{ Consistent } & \multicolumn{2}{l}{ Inconsistent } & F-test & \multicolumn{3}{l|}{ t-test } \\
\cline { 2 - 9 } & Mean & std & Mean & std & F-value & P-value & t-value & P-value \\
\hline 2 & 0.033 & 0.307 & 0.156 & 0.158 & 3.797 & 0.001 & -2.237 & 0.028 \\
\hline 3 & 0.117 & 0.287 & 0.225 & 0.222 & 1.662 & 0.189 & -1.607 & 0.113 \\
\hline 4 & 0.214 & 0.257 & 0.319 & 0.242 & 1.127 & 0.776 & -1.664 & 0.101 \\
\hline 5 & 0.331 & 0.26 & 0.365 & 0.203 & 1.636 & 0.203 & -0.565 & 0.574 \\
\hline 6 & 0.401 & 0.275 & 0.304 & 0.272 & 1.024 & 0.981 & 1.419 & 0.16 \\
\hline 7 & 0.555 & 0.35 & 0.341 & 0.3 & 1.355 & 0.435 & 2.569 & 0.012 \\
\hline 8 & 0.561 & 0.377 & 0.376 & 0.331 & 1.299 & 0.504 & 2.042 & 0.045 \\
\hline
\end{tabular}

Table 6

Chi-square test for PANSS drop percentages

\begin{tabular}{|lllll|}
\hline PANSS drop (\%) & Consistent $(\mathrm{N}=\mathbf{4 8})$ & Inconsistent (N-24) & chi-square & P-value \\
\hline$>=25$ & 37 & 16 & 0.438 & 0.508 \\
\hline$<25$ & 11 & 8 & & \\
\hline$>=50$ & 24 & 8 & 1.188 & 0.276 \\
\hline$<50$ & 24 & 16 & 5.314 & 0.021 \\
\hline$>=75$ & 15 & 1 & & \\
\hline$<75$ & 33 & 23 & & \\
\hline Abbreviations: PANSS, Positive and Negative Syndrome Scale. & & \\
\hline
\end{tabular}

After the time point 6 (16 weeks after the baseline level), the PANSS scores for the cohorts in the 'consistent' group start to get lower than for those in the 'inconsistent' group, although it is statistically insignificant at that point. However, the trend becomes more obvious after that. The PANSS differences for the two groups are statistically significant at the time point 7 (20 weeks after), and both the PANSS 
differences and the PANSS dropping rate are statistically significant at the time point 8 (24 weeks after). Overall, the PANSS scores for the cohorts in the 'consistent' group changed larger than for those in the 'inconsistent' group (Table 6).

In our algorithm design, most drugs are put in the 'Use with caution' or 'Use with caution and with frequent blood concentration monitoring' categories because their potential adverse reactions or because the patient was either ultra-rapid or poor metabolizer for those drugs. So while it may sound surprising, it is still understandable that antipsychotics in these categories were also effective since the PANSS score was the only index we considered in this study. However, our results indicated that in the longer term, it is still those who were initially in the 'Use as directed' column had better treatment efficacy. The reasons may lie in the fact that the genetic profiles of those cohorts' in the 'Use as directed' column are matched better with their drug use, or because in the actual practice, cohorts who were in the 'Use with caution' or 'Use with caution and with frequent blood concentration monitoring' did not get adequate monitoring we recommended.

\section{Discussions}

A variety of antipsychotics are metabolized mainly through CYP2D6[19, 21-23]. CYP2D6*10 is a high frequency mutation in the Chinese population that leads to a decrease in enzyme activity, which may increase the blood concentration and peak value of drugs metabolized by CYP2D6 and affect the therapeutic effectiveness and toxic side effects. Copy number variation (CNV) of CYP2D6 is another factor which may greatly change someone's drug metabolizing ability[24]. The polyploidy frequency of CYP2D6 gene reaches up to 45\% in Asian[25] and creates a higher occurrence frequency of ultra-rapid metabolizers than Caucasians (around 7\%)[24]. This is not reflected in our data because the design of our program heavily penalize those ultra-rapid metabolizers, which means they would almost certain be placed in the 'Use with caution' or 'Use with caution and with frequent blood concentration monitoring' categories. As a matter of fact, among the four SGAs remained in the final study, the CYP2D6 genotypes were only considered in the placement of aripiprazole, based on the recommendations of FDA. The metabolic process of quetiapine is mainly regulated by the CYP3A4/5 activity[26, 27]. And for clozapine and olanzapine, the gene-drug interaction may exist in spite of the current literature reports regarding this issue are inconclusive[20] and no CYP2D6 testing are recommended.

CYP1A2 also regulate the metabolizing of some antipsychotics including olanzapine[28-31]. CYP1A2*1F and CYP1A2* $1 \mathrm{C}$ are important mutation types in East Asian populations. CYP1A2*1F mutation will increase the metabolic activity of CYP1A2 enzyme, while CYP1A2* $1 \mathrm{C}$ will decrease the metabolic activity of CYP1A2[32]. The occurrence frequency of CYP1A2*1F mutation can reach up to $40 \%$ or above, therefore it is not surprising that so many cohorts in this study were CYP1A2 ultra-rapid metabolizers.

DRD2 is a dopamine receptor targeted by many antipsychotics [33-36]. The polymorphisms of rs1079597, rs1799732 and rs1799978 can affect the efficacy of various antipsychotics. MC4R is a melanocyte stimulating hormone receptor, which plays an important role in controlling weight gain. 
Weight gain is a common side effect of second-generation antipsychotics, and the single nucleotide polymorphism site rs489693 of MC4R is associated with the weight gain side effects of multiple antipsychotics [37-39]. HTR1A is the serotonin receptor and the target of some antipsychotics drugs, such as quetiapine[ $[40,41]$. Therefore, the accurate genotyping results for these gene loci will provide an important basis for doctors' clinical individualized medication.

This clinical study was taken place in Hulunbuir, a perfecture of Inner Mongolia Autonomous Region, China. Ethnical difference was one of the research goals we had in mind when the study was initially designed. However, we ultimately decided to leave out all ethnical minority groups, including Mongol, Manchu, Oroqen, Ewenki, Daur et al, because the number of the cohorts in these groups were not large enough to get statistically meaningful results.

The results obtained in this study demonstrate that genetic test is useful in guiding the treatment of schizophrenia, although this trial should just be considered a beginning. The number of cohorts who finished the entire study is low, and we only used PANSS as the evaluation criteria. As a matter of fact, there are quite a few other indexes, such as RSESE (A Rating Scale for Extrapyramidal Side Effects) and UKU Side Effect Rating Scale, can be used to evaluate the side effects of the prescribed drugs. Also, we may also include pharmacoeconomics measures to indicate how much medical costs the guided medication may save versus unguided ones. In the near future, we plan to carry out larger-scale, randomized, multi-centered, double-blinded study to further validate the hypothesis that schizophrenia treatment guided by this program will be more effective than the unguided ones.

\section{Conclusion}

Precision medicine is the trend for future medical practices. While there were already quite a few successful reports about the pharmacogenomic-based genetic test guiding the treatment for psychiatric diseases in North American and European clinical services[8-16], there were still voices in China arguing against it[42]. One major practical conclusion we can get from this study, is that patients whose genetic profiles match their medication treatment tend to have better efficacy in the long term. This is in addition to other benefits which are not reflected in this study, such as lower ADR risks and highlighted alarm for blood concentration monitoring. Therefore, genetic test is highly recommended for those receiving antipsychotic medications for treating schizophrenia.

\section{Abbreviations}

PANSS, Positive and Negative Syndrome Scale; CYP1A2, cytochrome P450 1 A2 gene; CYP2D6, cytochrome P450 2D6 gene; CYP3A4, cytochrome P450 3A4 gene; UM, Ultra-rapid Metabolizer; EM, Extensive Metabolizer; IM, Intermediate Metabolizer; PM, Poor Metabolizer; ADR, adverse drug reaction; DRD2, dopamine 2 receptor gene; HTR1A, 5-Hydroxytryptamine Receptor 1A gene; HTR2C, 5Hydroxytryptamine Receptor $2 \mathrm{C}$ gene; $M C 4 R$, melanocortin4 receptor gene. SNP, single nucleotide polymorphism site: MDD: Major depressive disorder; IMPACT: Individualized Medicine: Pharmacogenetics 


\section{Declarations}

\section{Ethics approval and consent to participate}

This study was approved by the Medical Ethics Committee of Hulunbuir Mental Health Center (approval number: 2018-051) and all subjects provided written informed consent in accordance with the Helsinki declaration. As all data was entered in a completely anonymized manner, consent to participate was not required.

\section{Consent for publication}

As completely anonymized observational data was used (see "Ethics approval and consent to participate"), consent for publication was not required.

\section{Availability of data and materials}

The dataset used in the analysis of this study is available upon reasonable request and with permission of Shanghai Conlight Medical Institute and Hulunbuir Mental Health Center.

\section{Competing interests}

The authors declare no conflicts of interest associated with this research study.

\section{Funding}

This study is supported by Inner Mongolia Science \& Technology Plan (grant No. 2018011). The funder, $\mathrm{XZ}$, participated in study designing, protocol writing and data collection.

\section{Authors' contributions}

All authors contributed substantially and meaningfully to this study and the final manuscript. XZ and YS designed the study and wrote the protocol. DDQ led the recruitment and the data collection phase. XG conducted data analysis. $\mathrm{CH}$ and $\mathrm{YZ}$ developed the algorithm. YS wrote the first draft of the manuscript and all authors have approved the final manuscript. 


\section{Acknowledgments}

The authors wish to thank Dr. Botao Liu, for his useful comment on this manuscript.

\section{References}

1. Trakadis YJ, Sardaar S, Chen A, Fulginiti V, Krishnan A. Machine learning in schizophrenia genomics, a case-control study using 5,090 exomes. American journal of medical genetics Part B Neuropsychiatric genetics: the official publication of the International Society of Psychiatric Genetics. 2019;180(2):103-12.

2. Chong HY, Teoh SL, Wu DB, Kotirum S, Chiou CF, Chaiyakunapruk N. Global economic burden of schizophrenia: a systematic review. Neuropsychiatr Dis Treat. 2016;12:357-73.

3. Combs DRMK, Gutierrez MMI: Adult psychopathology and diagnosis. 6th edn. Edited by Hersen M BD: John Wiley \& Sons; 2011.

4. Reynolds GP, Yao Z, Zhang X, Sun J, Zhang Z. Pharmacogenetics of treatment in first-episode schizophrenia: D3 and 5-HT2C receptor polymorphisms separately associate with positive and negative symptom response. European neuropsychopharmacology: the journal of the European College of Neuropsychopharmacology. 2005;15(2):143-51.

5. Kaddurah-Daouk R, Weinshilboum R, Pharmacometabolomics Research N. Metabolomic Signatures for Drug Response Phenotypes: Pharmacometabolomics Enables Precision Medicine. Clin Pharmacol Ther. 2015;98(1):71-5.

6. Shukla SK, Murali NS, Brilliant MH. Personalized medicine going precise: from genomics to microbiomics. Trends Mol Med. 2015;21(8):461-2.

7. Lyman GH, Moses HL. Biomarker Tests for Molecularly Targeted Therapies-The Key to Unlocking Precision Medicine. N Engl J Med. 2016;375(1):4-6.

8. Hall-Flavin DK, Winner JG, Allen JD, Jordan JJ, Nesheim RS, Snyder KA, Drews MS, Eisterhold LL, Biernacka JM, Mrazek DA. Using a pharmacogenomic algorithm to guide the treatment of depression. Translational psychiatry. 2012;2:e172.

9. Hall-Flavin DK, Winner JG, Allen JD, Carhart JM, Proctor B, Snyder KA, Drews MS, Eisterhold LL, Geske J, Mrazek DA. Utility of integrated pharmacogenomic testing to support the treatment of major depressive disorder in a psychiatric outpatient setting. Pharmacogenet Genomics. 2013;23(10):53548.

10. Benitez J, Jablonski MR, Allen JD, Winner JG. The clinical validity and utility of combinatorial pharmacogenomics: Enhancing patient outcomes. Applied translational genomics. 2015;5:47-9.

11. Altar CA, Carhart J, Allen JD, Hall-Flavin D, Winner J, Dechairo B. Clinical Utility of Combinatorial Pharmacogenomics-Guided Antidepressant Therapy: Evidence from Three Clinical Studies. Molecular neuropsychiatry. 2015;1(3):145-55. 
12. Winner JG, Dechairo B. Combinatorial Versus Individual Gene Pharmacogenomic Testing in Mental Health: A Perspective on Context and Implications on Clinical Utility. Yale J Biol Med. 2015;88(4):375-82.

13. Fields ES, Lorenz RA, Winner JG. Use of combinatorial pharmacogenomic testing in two cases from community psychiatry. Pharmacogenomics personalized medicine. 2016;9:79-84.

14. Greden JF, Parikh SV, Rothschild AJ, Thase ME, Dunlop BW, DeBattista C, Conway CR, Forester BP, Mondimore FM, Shelton RC, et al. Impact of pharmacogenomics on clinical outcomes in major depressive disorder in the GUIDED trial: A large, patient- and rater-blinded, randomized, controlled study. J Psychiatr Res. 2019;111:59-67.

15. Brown L, Vranjkovic O, Li J, Yu K, Al Habbab T, Johnson H, Brown K, Jablonski MR, Dechairo B. The clinical utility of combinatorial pharmacogenomic testing for patients with depression: a metaanalysis. Pharmacogenomics. 2020;21(8):559-69.

16. Herbert D, Neves-Pereira M, Baidya R, Cheema S, Groleau S, Shahmirian A, Tiwari AK, Zai CC, King N, Muller DJ, et al. Genetic testing as a supporting tool in prescribing psychiatric medication: Design and protocol of the IMPACT study. J Psychiatr Res. 2018;96:265-72.

17. Blake CM, Kharasch ED, Schwab M, Nagele P. A meta-analysis of CYP2D6 metabolizer phenotype and metoprolol pharmacokinetics. Clin Pharmacol Ther. 2013;94(3):394-9.

18. Kirchheiner J, Heesch C, Bauer S, Meisel C, Seringer A, Goldammer M, Tzvetkov M, Meineke I, Roots I, Brockmoller J. Impact of the ultrarapid metabolizer genotype of cytochrome P450 2D6 on metoprolol pharmacokinetics and pharmacodynamics. Clin Pharmacol Ther. 2004;76(4):302-12.

19. Zhou SF. Polymorphism of human cytochrome P450 2D6 and its clinical significance: Part I. Clin Pharmacokinet. 2009;48(11):689-723.

20. Swen JJ, Nijenhuis M, de Boer A, Grandia L, Maitland-van der Zee AH, Mulder H, Rongen GA, van Schaik RH, Schalekamp T, Touw DJ, et al. Pharmacogenetics: from bench to byte-an update of guidelines. Clin Pharmacol Ther. 2011;89(5):662-73.

21. Jukic MM, Smith RL, Haslemo T, Molden E, Ingelman-Sundberg M. Effect of CYP2D6 genotype on exposure and efficacy of risperidone and aripiprazole: a retrospective, cohort study. The lancet Psychiatry. 2019;6(5):418-26.

22. Zhou SF, Liu JP, Lai XS. Substrate specificity, inhibitors and regulation of human cytochrome P450 2D6 and implications in drug development. Curr Med Chem. 2009;16(21):2661-805.

23. Zhou SF. Polymorphism of human cytochrome P450 2D6 and its clinical significance: part II. Clin Pharmacokinet. 2009;48(12):761-804.

24. Steijns LS, Van Der Weide J. Ultrarapid drug metabolism: PCR-based detection of CYP2D6 gene duplication. Clinical chemistry. 1998;44(5):914-7.

25. Sistonen J, Fuselli S, Levo A, Sajantila A. CYP2D6 genotyping by a multiplex primer extension reaction. Clinical chemistry. 2005;51(7):1291-5.

26. Bakken GV, Molden E, Knutsen K, Lunder N, Hermann M. Metabolism of the active metabolite of quetiapine, N-desalkylquetiapine in vitro. Drug Metab Dispos Biol Fate Chem. 2012;40(9):1778-84. 
27. van der Weide $K$, van der Weide $J$. The influence of the CYP3A4*22 polymorphism on serum concentration of quetiapine in psychiatric patients. J Clin Psychopharmacol. 2014;34(2):256-60.

28. Wang B, Zhou SF. Synthetic and natural compounds that interact with human cytochrome P450 1A2 and implications in drug development. Curr Med Chem. 2009;16(31):4066-218.

29. Zhou SF, Yang LP, Zhou ZW, Liu YH, Chan E. Insights into the substrate specificity, inhibitors, regulation, and polymorphisms and the clinical impact of human cytochrome P450 1A2. AAPS J. 2009;11(3):481-94.

30. Zhou SF, Chan E, Zhou ZW, Xue CC, Lai X, Duan W: Insights into the structure, function, and regulation of human cytochrome P450 1A2. Current drug metabolism 2009, 10(7):713-729.

31. Hattori S, Suda A, Miyauchi M, Shiraishi Y, Saeki T, Fukushima T, Fujibayashi M, Tsujita N, Ishii C, Ishii $\mathrm{N}$, et al. The association of genetic polymorphisms in CYP1A2, UGT1A4, and ABCB1 with autonomic nervous system dysfunction in schizophrenia patients treated with olanzapine. BMC Psychiatry. 2020;20(1):72.

32. Na Takuathung M, Hanprasertpong N, Teekachunhatean S, Koonrungsesomboon N. Impact of CYP1A2 genetic polymorphisms on pharmacokinetics of antipsychotic drugs: a systematic review and meta-analysis. Acta psychiatrica Scandinavica. 2019;139(1):15-25.

33. Houston J, Dharia S, Bishop JR, Ellingrod VL, Fijal B, Jacobson JG, Hoffmann VP. Association of DRD2 and ANKK1 polymorphisms with prolactin increase in olanzapine-treated women. Psychiatry research. 2011;187(1-2):74-9.

34. Kim E, Kwon JS, Shin YW, Lee JS, Kang WJ, Jo HJ, Lee JM, Yu KS, Kang DH, Cho JY, et al. Taq1A polymorphism in the dopamine $\mathrm{D} 2$ receptor gene predicts brain metabolic response to aripiprazole in healthy male volunteers. Pharmacogenet Genomics. 2008;18(2):91-7.

35. Kwon JS, Kim E, Kang DH, Choi JS, Yu KS, Jang IJ, Shin SG, group As: Taq1A polymorphism in the dopamine D2 receptor gene as a predictor of clinical response to aripiprazole. European neuropsychopharmacology: the journal of the European College of Neuropsychopharmacology 2008, 18(12):897-907.

36. Lencz T, Robinson DG, Xu K, Ekholm J, Sevy S, Gunduz-Bruce H, Woerner MG, Kane JM, Goldman D, Malhotra AK. DRD2 promoter region variation as a predictor of sustained response to antipsychotic medication in first-episode schizophrenia patients. Am J Psychiatry. 2006;163(3):529-31.

37. Chowdhury NI, Tiwari AK, Souza RP, Zai CC, Shaikh SA, Chen S, Liu F, Lieberman JA, Meltzer HY, Malhotra AK, et al. Genetic association study between antipsychotic-induced weight gain and the melanocortin-4 receptor gene. The pharmacogenomics journal. 2013;13(3):272-9.

38. Czerwensky F, Leucht S, Steimer W. MC4R rs489693: a clinical risk factor for second generation antipsychotic-related weight gain? The international journal of neuropsychopharmacology. 2013;16(9):2103-9.

39. Malhotra AK, Correll CU, Chowdhury NI, Muller DJ, Gregersen PK, Lee AT, Tiwari AK, Kane JM, Fleischhacker WW, Kahn RS, et al. Association between common variants near the melanocortin 4 
receptor gene and severe antipsychotic drug-induced weight gain. Arch Gen Psychiatry. 2012;69(9):904-12.

40. Jordan S, Koprivica V, Chen R, Tottori K, Kikuchi T, Altar CA. The antipsychotic aripiprazole is a potent, partial agonist at the human 5-HT1A receptor. Eur J Pharmacol. 2002;441(3):137-40.

41. Lerond J, Lothe A, Ryvlin P, Bouvard S, d'Amato T, Ciumas C, Dalery J, Poulet E, Saoud M. Effects of aripiprazole, risperidone, and olanzapine on 5-HT1A receptors in patients with schizophrenia. J Clin Psychopharmacol. 2013;33(1):84-9.

42. Shan X, Zhao W, Qiu Y, Wu H, Chen J, Fang Y, Guo W, Li L. Preliminary Clinical Investigation of Combinatorial Pharmacogenomic Testing for the Optimized Treatment of Depression: A Randomized Single-Blind Study. Front NeuroSci. 2019;13:960.

\section{Figures}

\begin{tabular}{|c|c|c|}
\hline Use as Directed & Use with Caution & $\begin{array}{l}\text { Use with caution and with frequent } \\
\text { blood concentration monitoring }\end{array}$ \\
\hline $\begin{array}{l}\text { Paliperidone }[5,7] \\
\text { Ziprasidone }[5,7]\end{array}$ & $\begin{array}{c}\text { Amisulpride }[6,7] \\
\text { Aripiprazole }[1,6,7] \\
\text { Clozapine }[6,8] \\
\text { Olanzapine }[6,8] \\
\text { Quetiapine }[3,6,7] \\
\text { Risperidone }[1,5,8] \\
\text { Haloperidol }[1,6,8] \\
\text { Perphenazine }[1,5,8] \\
\text { Zuclopenthixol [1, 8] } \\
\text { Sulpiride }[6,8] \\
\text { Loxapine }[1,6,8] \\
\text { Perospirone }[1,8]\end{array}$ & $\begin{array}{c}\text { Thioridazine }[2 / 1,8] \\
\text { Chlorpromazine }[2,6,8]\end{array}$ \\
\hline
\end{tabular}

Annotation:

[1] (Extensive Metabolizer) Drug metabolism at normal level, blood concentration within effective range

[2] (Ultra-rapid Metabolizer) Drug metabolism accelerates, blood concentration may drop below effective range

[3] (Intermediate Metabolizer) Drug metabolism slows, blood concentration may increase over the safe limit

[4] (Poor Metabolizer) Drug metabolism slows, blood concentration may increase over the safe limit which leads to ADR

[5] Response well to the drug

[6] May not response well to the drug

[7] Low ADR

[8] High ADR

\section{Figure 1}

A sample report. Based on the genetic test results for a certain patient, the 16 included antipsychotics were assigned into one of the three columns: 'Use as directed' (green bin), 'Use with caution' (yellow bin), or 'Use with caution and with frequent blood concentration monitoring' (red bin). The numbers in the brackets following drug names explained the reasons why the drug was assigned this way. Numbers 1-4 
indicated the metabolizer types of the major metabolizing enzyme for that drug. If more than one enzymes were tested, for instance, thioridazine, for which both CYP1A2 and CYP2D 6 were tested, a forward slash was used to separate the metabolizer types for the two enzymes. Numbers 5-6 indicated whether or not the patient might respond well to the drug. Numbers 7-8 indicated whether the patient might have high or low risks for adverse drug reactions. Due to limited research reports, some drugs may not be able to find related genetic loci to cover all three factors listed above (metabolism, efficacy and $A D R)$.

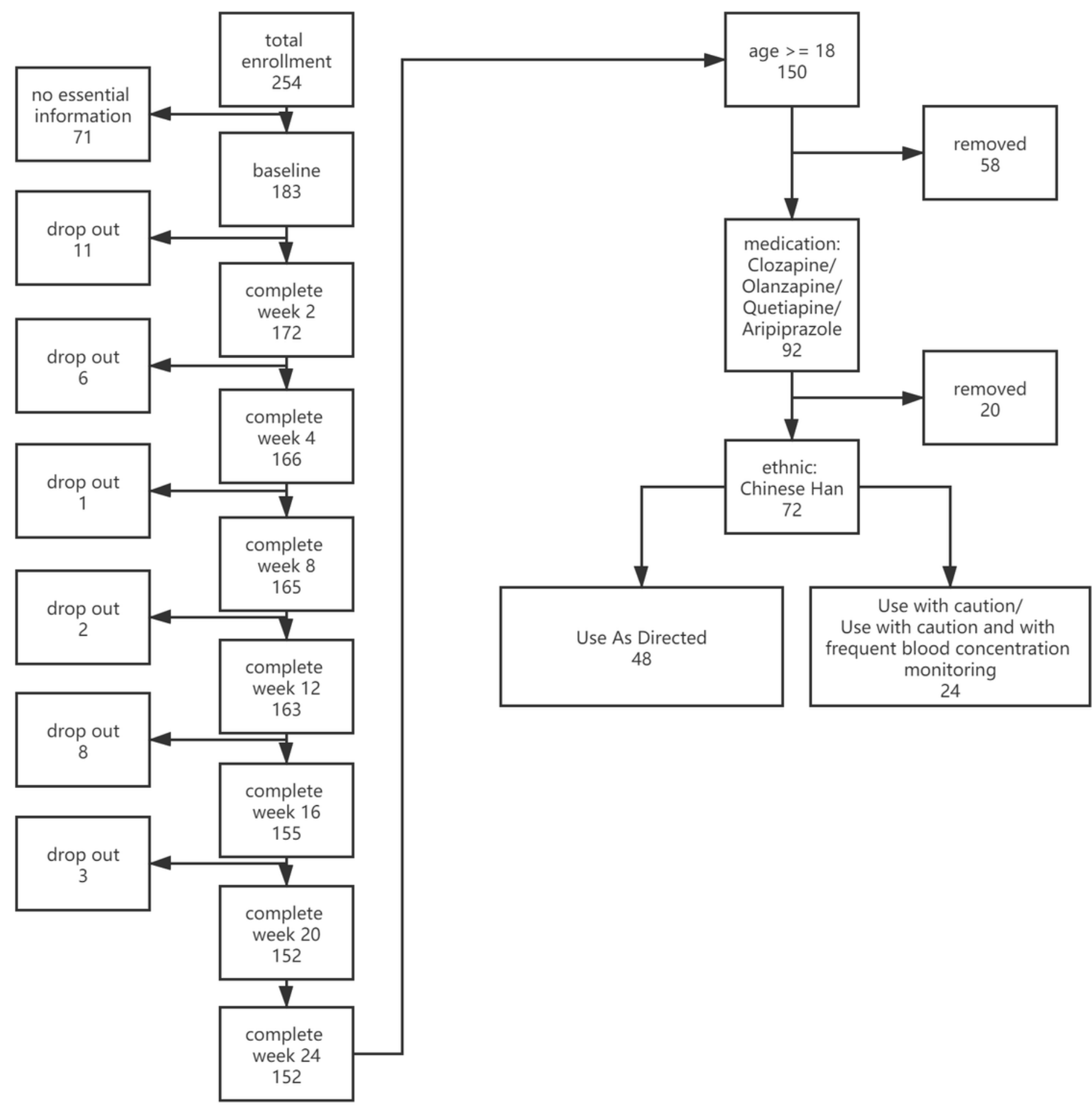

Figure 2 
Chart of Study Profile

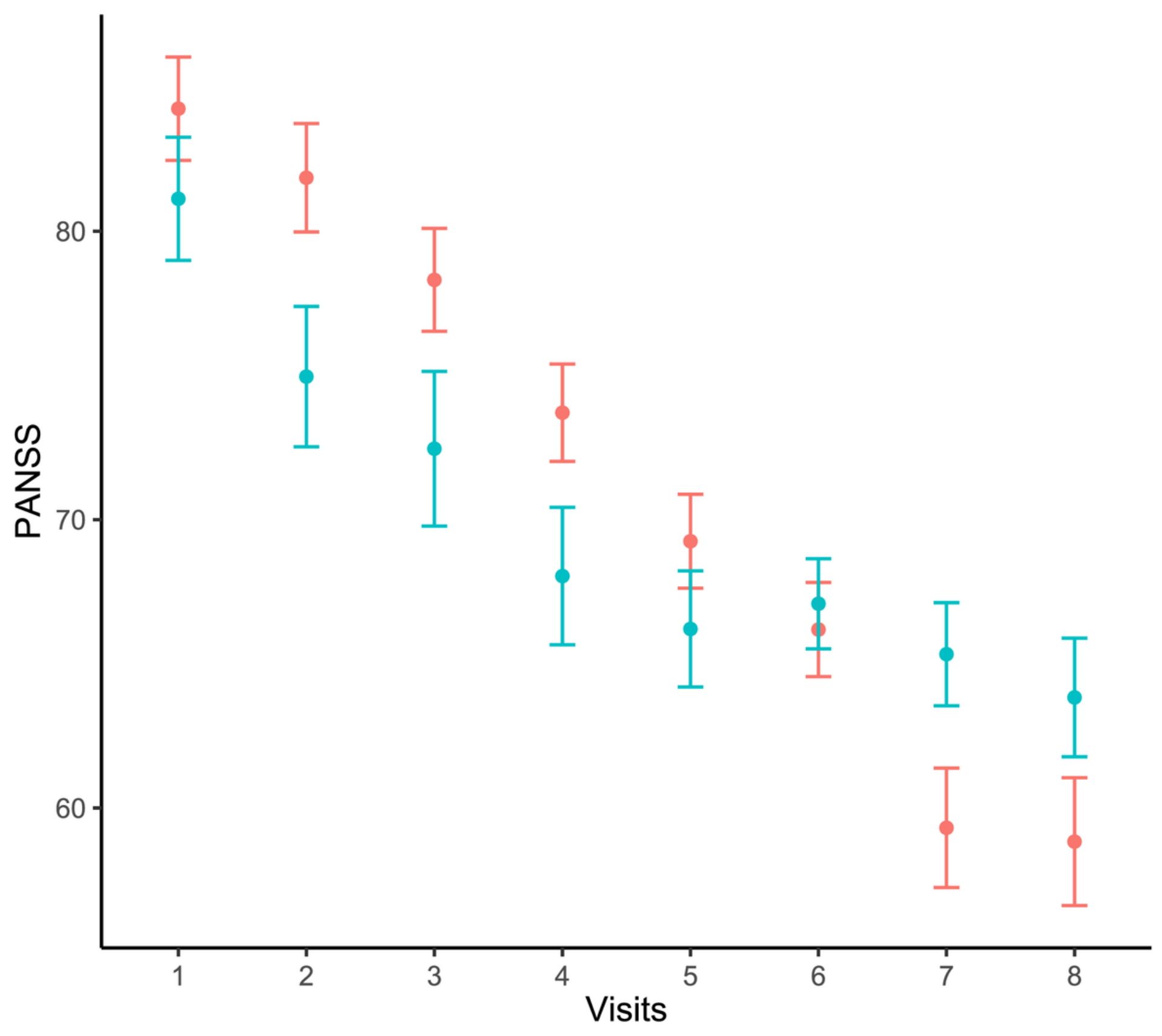

Groups -- Consistent $\multimap-$ Inconsistent

Figure 3

PANSS scores at each time points for the two groups. Points represent mean scores for each group at each time point. Bars represent SD. PANSS, Positive and Negative Syndrome Scale. 


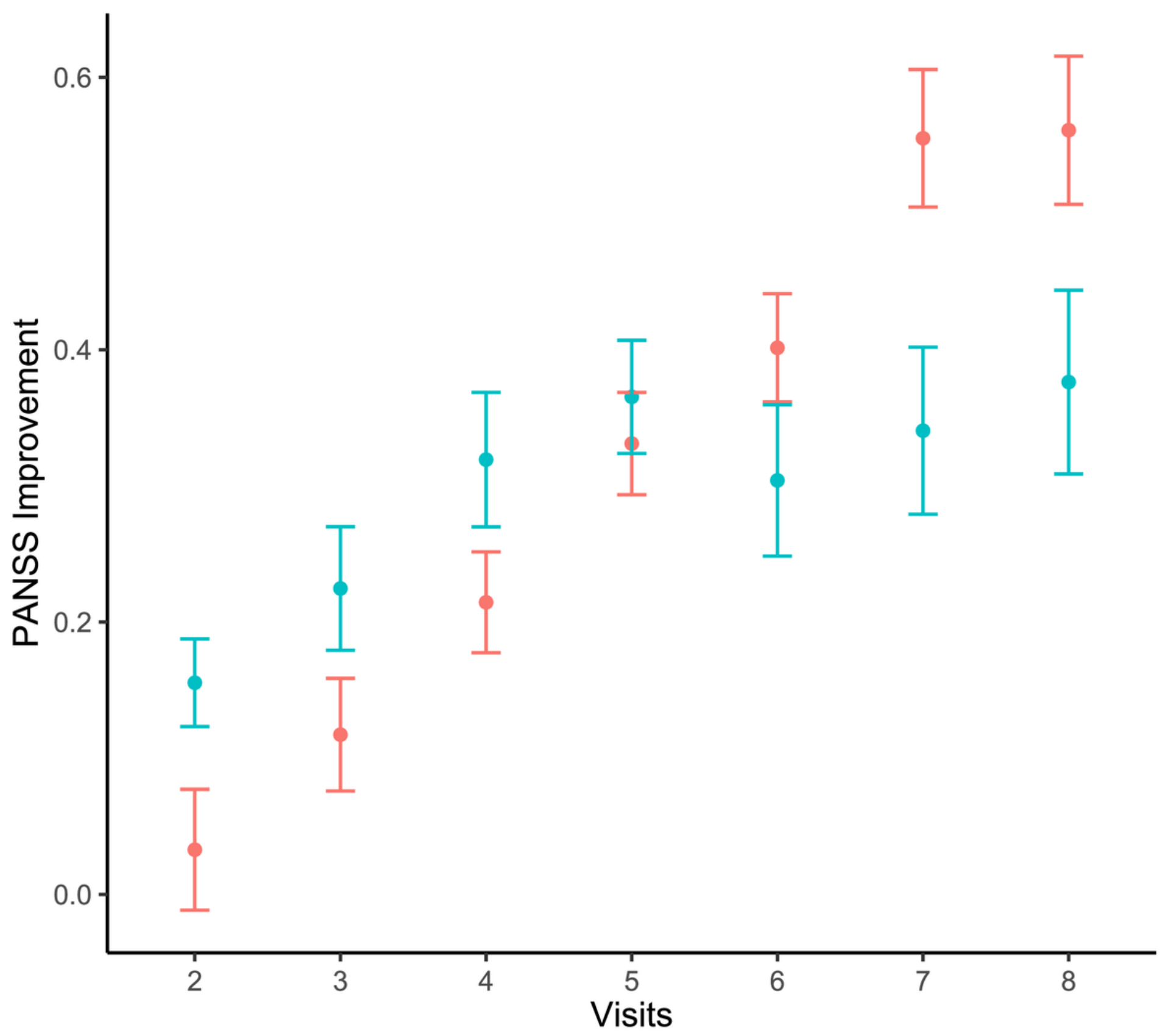

Groups $\rightarrow$ Consistent $\rightarrow$ Inconsistent

\section{Figure 4}

PANSS drop rates at each time points for the two groups. Points represent mean scores for each group at each time point. Bars represent SD. PANSS, Positive and Negative Syndrome Scale.

\section{Supplementary Files}

This is a list of supplementary files associated with this preprint. Click to download. 
- Figure4.svg

- Figure3.svg

- Figure2.svg

- Figure1.svg

- supplementarytable.xlsx 